\title{
TEM Study of Stability of Inverted Photovoltaic (PV) Cells
}

\author{
Y.J. Suh, ${ }^{*}$ S.Y. Park, ${ }^{*}$ T.H. Lee, ${ }^{*}$ W.S. Chung, ${ }^{* *}$ and K.K. Kim, ${ }^{* *}$ M.J. Kim* \\ * Dept. of Materials Science \& Engineering, University of Texas at Dallas, Richardson, TX 75080, \\ U.S.A. \\ ** Korea Institute of Science and Technology, 39-1 Hawolgok-Dong, Seoul, 136-791, KOREA
}

Silicon solar cells, which have been in development for several decades, offer a clean, zero emission alternative to fossil fuels. Polymer solar cells built from thin films of organic semiconductors have various advantages over silicon based cells, such as lightweight, flexibility, disposability, and low fabrication cost [1]. However, conventional polymer PV cells, whose active layer is sandwiched between a high-work-function transparent indium tin oxide (ITO) anode and a low-work-function metal cathode, have short lifetimes. In order to improve cell stability, an inverted PV cell structure was proposed $[2,3]$. This structure enhances the stability to a level greater than that of conventional polymer PV cells by reversing the direction of charge flow. This is accomplished using a high work function metal $(\mathrm{Ag}, \mathrm{Au})$ as the hole collecting electrode and a metal oxide $\left(\mathrm{TiO}_{2}, \mathrm{ZnO}\right)$ as the electron selective contact, as shown in FIG. 1. Although the inverted cells show greater operational stability than conventional cells, their reliability is not within the acceptable range for real applications. In this study, the origin of instability in inverted polymer PV cells was investigated using HRTEM.

Inverted polymer PV cells were fabricated on the ITO/Glass substrate by sequentially spin coating and drying $\mathrm{TiO}_{2}$ nanoparticles, the active layer (P3HT:PCBM, with ratio of 1:0.8), and PEDOT:PSS. The silver top electrode was then deposited. Cross sectional TEM samples were prepared from a device stored in dark for three months after fabrication and the device additionally exposed to ambient environment for eleven weeks after the lightless storage period using a FEI Nova 200 NanoLab focused ion beam (FIB). HRTEM and EDAX analyses were conducted using JEM-2100F.

FIG. 2a shows a cross sectional HRTEM image of an inverted polymer PV cell stored in dark for three months after fabrication. The interface between the silver electrode and PEDOT:PSS layer is clear and well defined. In contrast, there is a noticeable change in the interface for the sample stored in ambient lighting for eleven weeks (FIG. 2b). The change mainly occurred in the top silver electrode and PEDOT:PSS layer. Various crystalline particles were observed in the PEDOT:PSS layer, as shown in an inset of FIG. 2b. EDAX analysis confirmed that the particles consist of silver (FIG. 2c). Considering that the morphology change of silver is localized at the interface with PEDOT:PSS layer, it appears that this change came from the reaction between the two layers. The fact that no morphology change in the top electrode was observed after storage for three months in dark indicates that light is involved in the reaction. Sudden drops in device performance during operation in inverted PV cells (FIG. 1) suggest that this reaction is accelerated during light exposure. Nano-structural and chemical analyses of the interfacial reactions will be given and discussed in detail.

[1] K.M. Coakley and M.D. McGehee, Chem. Mater. 16 (2004) 4533-4542.

[2] S.H. Park et al., Nature Photonics. 3 (2009) 297.

[3] S.K. Hau et al., Applied Physics Letters. 92 (2008) 253301.

[4] This research was supported by a grant(code \#: 2009K000469) from 'CNMT' under '21st Century Frontier R\&D Programs' of the MEST, Korea. 


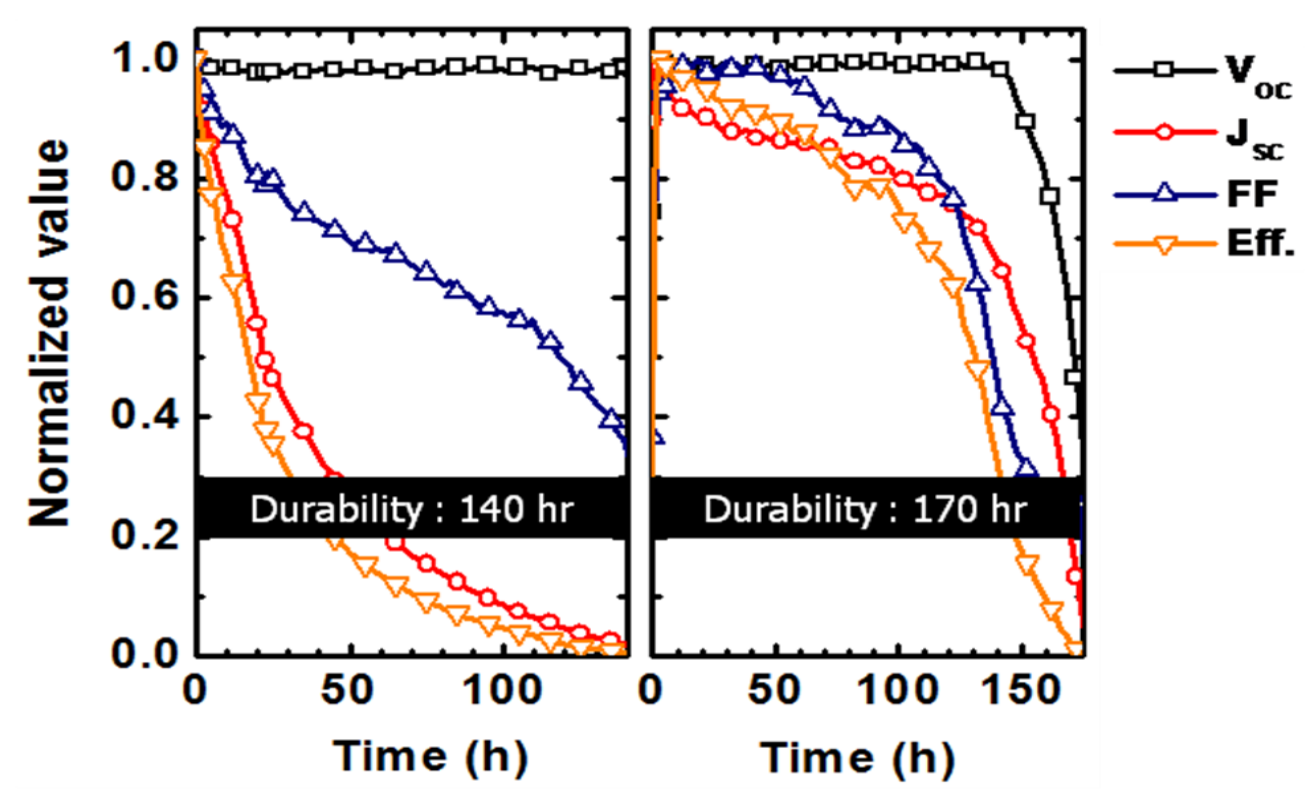

FIG. 1. Degradation of electrical performances (open circuit voltage $\left(\mathrm{V}_{\mathrm{OC}}\right)$, short circuit current $\left(\mathrm{J}_{\mathrm{SC}}\right)$, fill factor $(\mathrm{FF})$, and energy conversion efficiency $\left(\mathrm{E}_{\mathrm{ff}}\right)$ ) of conventional polymer PV cell (left) and inverted polymer PV cell (right) during the reliability tests. Durability was determined when $E_{\mathrm{ff}}$. becomes zero.
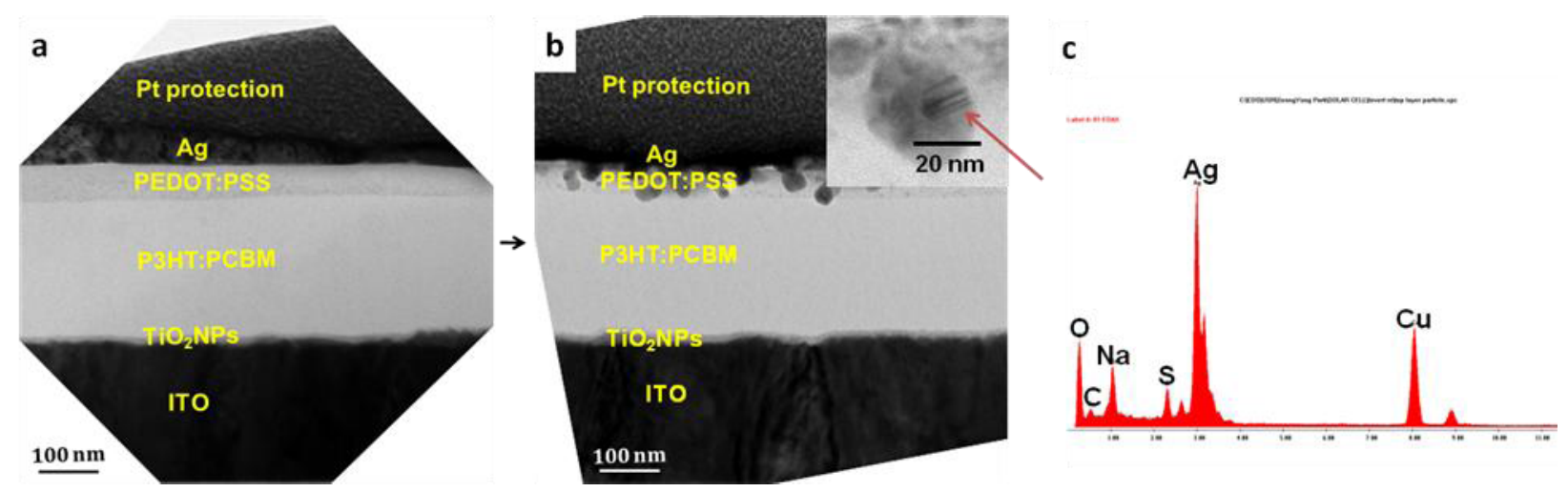

FIG. 2. Cross sectional HRTEM images showing the interface between silver and PEDOT:PSS layer of inverted polymer PV cell conserved in dark for three months after fabrication (a) and after additionally exposure to ambient environment for eleven weeks (b). Inset in (b) is an enlarged image of silver particles formed at the interface. (c) EDAX spectrum measured on the silver particle. 